\section{As velhas crises mundiais}

Osvaldo COGGIOLA. As grandes depressões (18731896 e 1929-1939): fundamentos econômicos, consequências geopoliticas e liçôes para o presente. São Paulo, Alameda, 2009. 245 páginas.

\section{Eduardo Silveira Netto Nunes}

A explosão da bolha imobiliária nos Estados Unidos em 2008 foi um dos fatores de expressão de uma crise que estava em formação nos últimos anos no centro do mundo capitalista, fundamentada na expansão desmedida da especulação financeira, patrocinada por bancos e investidores que inventavam capital com a reprodução de derivativos e expectativas de crescimento da economia mundial sem o devido lastro material e produtivo.

Tal crise, que continua a ter reflexos em todo o planeta, não foi fruto de um acontecimento isolado na história do sistema econômico mundial, pois se insere num percurso de crises mais intensas, segundo Coggiola, periódicas e típicas da economia capitalista como a de 1873-1896 (engendrada na Inglaterra) e a de 1929-1939 (emulada nos Estados Unidos).

Extremamente oportuno, o livro procura analisar as teorias liberais e, principalmente, marxistas das crises econômicas, apresentando um balanço das consequências dramáticas à humanidade produzidas pelas depressões (desemprego, redução da produção, fome, aumento da desigualdade, conflitos bélicos, xenofobia, ultra-nacionalismo, imperialismo). Apesar de ajudar a compreender o processo que leva às crises de efeitos globais e suas consequências, a preocupação do autor não recai em estudar este último abalo econômico desvelado em 2008. Seu interesse é apresentar o percurso das crises do sistema capitalista desde o momento em que elas passaram a ter efeitos globais, por isso sua periodização parte do abalo financeiro de 18731896 e chega ao crash de 1929-1939.

O livro está organizado em três capítulos: (1) "Considerações iniciais"; (2) "Século XIX, do auge à crise"; (3) "A crise de 1929 e a segunda 'grande depressão". Contém ainda uma bibliografia de referência interessante e diversificada sobre o tema das crises econômicas mundiais e uma introdução escrita pelo professor da Universidade Estadual de Campinas, Plínio de Arruda Sampaio Júnior.

A atualidade do livro, apesar de o autor centrar o seu conteúdo na análise das crises de 1873 e de 1929, deve-se ao vínculo de continuidade estabelecido entre o processo histórico que atravessa essas duas depressões, que chegaria também ao abalo financeiro de 2008: a condição estrutural do capitalismo como um sistema econômico no qual a existência de crises esporádicas seria constituinte de seu modo de ser e se organizar.

O caráter "cíclico" das crises é apresentado como o principal eixo interpretativo, e hipótese defendida ao longo do livro. Isso porque esse modelo econômico e de produção conteria em si as contradições estruturais de sua reprodução e expansão, que inevitavelmente para seguir adiante de tempos em tempos teria de se reorientar, destruir parte dos fatores que levaram à crise, expurgando de alguma maneira o capital e a produção excessiva, as rendas usurárias, a especulação, a distribuição da riqueza, o trabalho. Em contrapartida, nas crises, aqueles que a desencadearam em maior dimensão, os grandes especuladores, investidores, rentistas e capitalistas, ainda que fossem atingidos tenderiam a incrementar a concentração dos diferentes setores e negócios da economia depreciados, falidos e encerrados por conta da depressão.

Para identificar esse "processo" cíclico do capitalismo, o autor desenvolveu um debate teórico no primeiro capítulo do livro, no qual retoma as ideias de Karl Marx sobre a origem das crises econômicas como algo constituinte do sistema capitalista e não como um "desvio", um acidente. Citando Marx, ele afirma: "as crises do mercado mundial devem ser concebidas como a concentração real e a compensação violenta de todas as contradições da economia burguesa. [A crise] é o violento reestabelecimento da unidade entre [momentos] independentes e a violenta independização de momentos que, essencialmente, são a mesma coisa. Todas as contradiçôes da produção burguesa atingem coletivamente a explosão nas crises mundiais gerais" (p. 41).

$\mathrm{O}$ autor enfatizou também como as teorias liberais obscureciam a capacidade de entender o evento das depressões econômicas de maior vulto, uma vez que não ofereciam uma compreensão es- 
trutural, sendo que "antes de Marx, ninguém conseguira deduzir os limites da produção capitalista como algo que lhe fosse imanente e lhe denunciasse sua historicidade e transitoriedade: a auto-expansão do capital possui contradições incuráveis", sentencia o autor (p. 69). A resolubilidade transitória da crise seria possível (e o autor procura mostrar que assim o fora em 1873 e 1929) pela destruição das forças produtivas, na qual alguns seriam mais afetados que outros, até o momento da próxima depressão. A resolução definitiva, entretanto, viria apenas com a revolução social, que produziria a substituição do modo de produção capitalista pelo socialista, segundo o autor, inspirado em Marx. E como ela não veio nos países capitalistas centrais, resta a análise das circunstâncias diretas das crises mais agudas enfrentadas pelo sistema, e é o que está proposto nos dois outros capítulos.

O segundo capítulo dedica-se a analisar o desenvolvimento da crise iniciada em 1873, e a sua superação na última década do século XIX. A característica dessa depressão, e que a distinguiu de outras anteriores, foi sua dimensão econômica mundial e seu caráter geral, não tendo sido apenas setorial e nacional. Ela teria iniciado com o "craque da Bolsa de Viena" e ao atingir a "economia inglesa”, em vista do seu papel central no capitalismo da época, ganhou escala mundial (p. 71).

$\mathrm{O}$ autor descreve as causas e as consequências mais imediatas da crise, que variavam conforme o país analisado: falências bancárias na Áustria, nos Estados Unidos e na Alemanha, país que também se defrontou com o aumento dos custos de sua indústria e a queda da sua rentabilidade; baixa de preços de atacado em diversos países - Grã-Bretanha, 32\%, Alemanha, 40\%, França, 43\%, Estados Unidos, $45 \%$ - ; superprodução de mercadorias, redução da taxa de lucro e dos salários; desemprego; falências como na Inglaterra que, em 1873, se defrontou com cerca de 7490 e em 1879 com 13.130 .

A influência e o impacto dessa depressão no quadro geopolítico também mereceram atenção, isso porque a sua superação esteve relacionada com a expansão do capitalismo numa nova fase: a do imperialismo, facilitada pela emergência de grandes corporaçōes, concentração econômica e controle de mercados, e pela partição da África entre países imperiais simbolizada na Conferência de Berlim de 1884, e que expressava, segundo Engels, citado por Coggiola, o "botim pelas suas companhias" (p. 83). A esse respeito foram apresentados dados comparativos das possessões imperiais em 1876 e 1900. $\mathrm{Na}$ África, de 10,8\% pulou para 90,4\%; na Polinésia, de 56,8\% para 98,9\%; na Ásia, de 51,5\% para 56,6\%; na América, de 27,5\% para 27,2\%. Em resumo, quase a totalidade da África e da Polinésia, a metade da Ásia e um terço da América estavam sob administração imperial de países como a Inglaterra, Rússia, França, Alemanha, Estados Unidos, Japão, Bélgica e Holanda. Parte dos conflitos entre os impérios seria dissolvido em sangrentas guerras (inclui-se aí a Primeira Guerra Mundial), que combinavam interesses estatais e financeiros como algo imanente ao próprio sistema econômico e de poder mundial-imperial. A expansão imperial e a guerra mundial, na opinião de Coggiola, deveram-se "à contradição entre o desenvolvimento mundial das forças produtivas capitalistas e o estreito marco dos Estados nacionais", e, assim, a "crise capitalista assumia dimensōes mundiais” (p. 129).

O terceiro capítulo problematiza a emergência e o desenvolvimento do crash econômico mundial de 1929 até o período da eclosão da Segunda Guerra Mundial. Se na antessala da Primeira Grande Guerra observavam-se os problemas propulsados pela débâcle financeira de 1876 e a delimitação do imperialismo com os conflitos insolúveis entre as grandes potências, nos antecedentes da depressão de 1929 foi relevante a herança emergida dos escombros do embate militar mundial deflagrado em 1914, expresso, segundo Coggiola, pelo fato de que a "economia norte-americana estava em pleno desenvolvimento", suas "indústrias produziam e exportavam em grande quantidades, principalmente para os países europeus", e "após a guerra" o quadro não mudou, com "vultuosos empréstimos" à Europa, que estava voltada à "reconstrução das indústrias e cidades, necessitando manter suas importaçôes, principalmente dos Estados Unidos” (p. 149).

A "crise anunciada" no coração da Bolsa de Nova York teria derivado de um crescimento robusto da produção dos Estados Unidos e de países fora da Europa (Coggiola mostra que, comparando 1913 a 1926 , o aumento foi de $26 \%$ para os 
Estados Unidos e $24 \%$ para os outros países não europeus), de uma baixa taxa de lucro, alta concentração da renda e de um nível "razoável de desemprego" (p. 148). O êxtase dos norte-americanos expressava-se por empréstimos concedidos pelos bancos a juros de $12 \%$ (com recursos captados do Federal Reserve à taxa de 5\%) para compra de ações na Bolsa, sendo que parte dos créditos tomados recebiam como garantia os títulos comprados. Como afirma o autor, "todo o mundo lucrava e a euforia difundia-se com a credulidade geral” (p. 145). Essas condições acabaram se tornando problemáticas quando as nações europeias "reconstruídas, diminuíram drasticamente a importação de produtos industrializados e agrícolas dos Estados Unidos” (p. 150) - dois dos pilares dessa economia -, o que acabou gerando aumento nos estoques por conta da superprodução, queda nas vendas, redução dos salários e desemprego causado por esses fatores e pela "progressiva mecanização da indústria e da agricultura” (p. 153).

Os prolegômenos da crise foram dando sinais até que "a orgia dos lucros estourou em 24 de outubro de 1929 " com a queda de $50 \%$ nas cotações da Bolsa de Valores de Nova York; nos dias que sucederam, o "pânico" tomou conta de acionistas. $\mathrm{Na}$ "Quinta-Feira negra”, 29 de outubro, “16,4 milhões de ações foram postas à venda”, e, na falta de compradores, chegaram a perder $80 \%$ de seu valor, desencadeando uma série de falências, e perdas de patrimônio de pequenos, médios e grandes investidores (pp. 154-155).

As consequências foram dramáticas. Nos Estados Unidos, houve redução de $80 \%$ na produção de automóveis; entre 1930 e 1933 faliram 106.769 empresas (fora os bancos); o desemprego chegou a 25,2\%; a renda nacional caiu de 87,4 bilhões em 1929 para 41,7 bilhões, e a massa salarial de 50 para 30 bilhões. No Mundo, o desemprego de 10 milhōes em 1929 atingiu a cifra de 30 milhões, numa época em que os sistemas de seguridade social eram praticamente inexistentes; o comércio mundial desabou reduzindo-se a um terço de seu valor entre 1929 e 1933; a produção industrial caiu em 50\% em certos países; as falências bancárias na Europa central não foram comuns, mas a atividade bancária sofreu muito.
Diante da intensidade da depressão, Coggiola destacou a mudança significativa desencadeada pelo papel desempenhado pelo Estado no interior dos países centrais. Se antes a voga era o Estado liberal, o desenrolar da crise fez com que o poder público passasse a exercer funções interventoras na organização da economia, na distribuição dos benefícios (seguridade social e previdência) e na proteção de seus mercados internos. Em outras palavras, "o papel do Estado capitalista" assumiu funçôes de “açambarcador, banqueiro e 'produtor', comprando e estocando (ou destruindo) a produção agrícola, salvando o sistema bancário através da 'socialização’ das perdas” (p. 188). O Estado como indutor do desenvolvimento capitalista, como partícipe na construção da estabilidade social, que alguns atribuem a uma fabulação teórica de John Maynanard Keynes - keynesianismo -, para Coggiola teve como antecedentes concretos as diversas políticas promovidas por Franklin Roosevelt e que passaram a ser chamadas New Deal (de "êxito bastante duvidoso", segundo o autor). Elas foram responsáveis pelo restabelecimento da economia norte-americana nos últimos anos da década de 1930, ainda que esta só seria plenamente consolidada com a entrada dos Estados Unidos na Segunda Guerra Mundial, quando então "a máquina bélica norte-americana começou a funcionar a todo vapor, revitalizando a economia dos Estados Unidos, e levando-a para um patamar de monopolização inédito na história mundial do capitalismo. [...] a produção industrial americana cresceu drasticamente e as taxas de desemprego caíram" (pp. 230 passim), atingindo a cifra de $1 \%$ no final da guerra!

O livro ainda faz uma avaliação do impacto que a Grande Depressão produziu na organização dos trabalhadores nos Estados Unidos, mostrando que a intervenção do Estado e sua aproximação com entidades já existentes, no intuito de criar convergências que permitissem a recuperação do país, teriam sido uma das causas principais da baixa expansão do movimento operário e da quase inexpressiva dimensão eleitoral de partidos de esquerda em solo norte-americano.

De outra parte, vincula a emergência de Adolf Hitler na Alemanha às consequências estruturais sofridas pelo país após 1929, cujo impacto na eco- 
nomia produziu desemprego e "subproletariazação" da média e da pequena burguesia. Segundo Coggiola, o governo socialista de então não conseguira dar respostas satisfatórias à população, cortando inclusive "fundos públicos de ajuda aos desempregados" (p. 214). Por outro lado, a inabilidade da esquerda alemã em compor uma frente única de oposição ao nazismo, o qual crescia paulatinamente com os êxitos eleitorais, facilitara o caminho de Hitler, cujo discurso às "classes médias desesperadas" era pautado por "xenofobia, racismo, nacionalismo exacerbado, demagogia anticapitalista" (p. 215).

Para o autor, diante das tramas do processo histórico, as crises foram momentos de oportunidade de superação do sistema, isso porque "a Segunda Guerra Mundial, tanto quanto a Primeira, estava inscrita nas relações econômicas e políticas internacionais do período, mas, não eram inevitáveis" (p. 230). Nesse contexto, se as massas trabalhadoras tivessem feito prevalecer a "solidariedade internacionalista", opondo-se à guerra, a história mundial poderia ter se defrontado com outro destino. $\mathrm{O}$ desenvolvimento do conflito mundial como decorrência, em parte, da "segunda maior depressão do capitalismo em escala mundial", que destruiu em larga escala as "forças produtivas", acabou por restaurar "o precário equilíbrio da acumulação de capital” (p. 232) sob a hegemonia bélica, militar e econômica dos Estados Unidos.

Se Coggiola não deu seguimento à análise das "crises cíclicas" do capitalismo mundial até a crise global deflagrada em 2008 a partir dos Estados Unidos, Plínio de Arruda Sampaio Júnior faz na introdução uma reflexão a esse respeito, reforçando a tese do caráter cíclico do capitalismo e a necessidade, nas palavras de Júnior, de se "destruir as forças produtivas" via revolução ou "socialização dos prejuízos" para o restabelecimento do sistema. Júnior lembra, entretanto, que no caso da escolha pela "socialização dos prejuízos", o efeito é a repetição de soluções anteriormente adotadas, o que resulta em desemprego, empobrecimento dos trabalhadores e das classes médias, concentração de riqueza em grandes corporaçôes e o risco de um conflito militar.

A história em seu aspecto dramático apresenta similitudes. Se existem riscos para o futuro, há também possibilidade de mudanças. Coggiola pro- põe "a emergência de uma nova sociedade, baseada na propriedade social, no poder dos trabalhadores e na solidariedade dos povos de todo mundo" (p. 233). Se isso é socialismo não sei, mas creio que existem outras rotas mais solidárias, altruístas e não violentas para a construção do amanhã. Este livro oferece, assim, não uma resposta, mas elementos para a compreensão e a interpretação dos processos que atravessaram a formação do capitalismo em sua dimensão mundial, cujas crises $(1873,1896,1929$, 1939 e 2008) seriam a expressão de desajustes estruturantes intrínsecos a este sistema.

\section{EDUARDO SILVEIRA NETTO NUNES é doutor em História Social na Universidade de São Paulo e professor na Universidade de Passo Fundo. E-mail: <edunettonunes@hotmail.com>.}

